\title{
Coping With Uprooting Stress During Domestic Educational Migration in China
}

\author{
Alexander S. English ${ }^{1}$ and Daniel S. Worlton ${ }^{2}$ \\ 1 Shanghai International Studies University, Shanghai, China \\ ${ }^{2}$ Beijing Language and Culture University, Beijing, China
}

\begin{abstract}
F or many youth, attending university is their first extended time away from home, and uprooting F stress can often lead to distress. The present research examines the impact of uprooting stress on educational Chinese migrants and how students cope with the unanticipated pressure of leaving home. Using a sample of recent first-year students, we employed a longitudinal design that allowed us to examine the interaction effect of coping strategies (primary and secondary coping) and stress at time 1 and their impact on anxiety at time 2. Results indicated primary coping exerted an interaction effect on stress, exacerbating the negative effects and leading to more anxiety at time 2, but secondary coping did not. Females also reported lower stress and anxiety. In conclusion, the impact of uprooting stress and coping on psychological symptoms suggests further research on internal Chinese migration should consider the impact of within-culture variation in Mainland China.
\end{abstract}

Keywords: China, internal migration, longitudinal research study, primary and secondary coping, psychological symptoms, uprooting stress

Leaving home, or uprooting, particularly for the first time, is stressful and is often marked by difficult experiences adjusting to the new environment. College is often the time when youth depart their familiar homeland and undergo psychological changes adjusting to a new environment. While studies have examined psychological distress of uprooting and homesickness (see the review by Scopelliti \& Tiberio, 2012), how youth cope with these difficulties of being away from home is unclear. Gender and nationality have been variables in research on homesickness and uprooting stress during college transitions, but the results are inconclusive as to whether males or females struggle more (Poyrazli \& Lopez, 2007). Coping with uprooting stress is a major issue in a country like China as millions engage in interprovincial migration for purposes of education. The present study intends to examine the longitudinal effects of uprooting, coping, and psychological adjustment on recent non-local, first-year Chinese university students.

\section{Uprooting as an Element of Social Change}

Humans have always been mobile, but as the term 'uprooting' implies, we put down roots and make social connections when we settle in one place. Uprooting has been defined generally as the process when one leaves one place (forced or self-imposed) to relocate to another place (Brown, 1980). While uprooting can occur at any time across one's lifespan, the first year transition to college has been regarded as major life event and has served as a subject of study for many decades (Sun, 2015).

College students are not immune to the negative effects of uprooting (uprooting stress) during their adjustment process. In general, researchers have agreed that the experience of uprooting (e.g., feelings of separation or homesickness) is directly linked to increased levels of depression, loneliness, and anxiety (Fisher \& Hood, 1988). Although Fisher and Hood (1988) found that college women experience more uprooting difficulties, Brewin, Furham, and Howes (1989) found that college men were more homesick. Interestingly, the literature has found a high prevalence of uprooting stress at some point in college students' transition for the majority of college students around the world, including the United Kingdom, the Netherlands, the United States, Turkey, New Zealand, Australia, and China (Fisher, 1986; Scharp, Paxman, \& Thomas, 2016; Stroebe, Van Vliet, Hewstone, \& Willis, 2002; Tao, Dong, Pratt, Hunsberger, \& Pancer, 2000; Urquhart \& Pooley, 2007). Research on geographic distance has also consistently found that college students whose families lived 
closer experience less homesickness (Stroebe et al, 2002; Tognoli, 2010). There is also a plethora of research that has attributed positive benefits to social support during university adjustment (see review by Hinderlie \& Kenny, 2002; Sun, 2015; Tao et al., 2000).

While transition to college presents major changes to domestic students, international students have also been prone to uprooting difficulties, particularly as they cross cultures in pursuit of higher education. Cross-cultural adaptation studies provide a useful theoretical framework for researching the relationship between stresscoping-adaptation for these situations. Demes and Geeraert (2015) followed over 2,500 international students ${ }^{1}$ for 2 years as they studied at various sites around the world and found a strong association between stress and psychological adaptation - that coping strategies reduced stress over time. While the authors focused on general acculturative stress (i.e., stress of adjusting to new culture), Ward (2001) highlighted the linkage among stress, homesickness, and maladaptation across international students. The most recent and relevant empirical evidence pointing to the association among uprooting, coping, and adjustment stems from a study by Szabo, Jose, and Ward (2016). Using a sample of international students from two cultural backgrounds (Asian and Western) in New Zealand, the longitudinal study found that uprooting stress was moderated by two coping constructs (explained in the next paragraph). Given that uprooting stress is considered uncontrollable due to the lack of familiarity in the new environment, primary coping exacerbated maladaptation and secondary coping buffered the negative effects on anxiety. This research study points out that university students (domestic and international) undergoing a college transition may experience difficulty in coping with the unknown, resulting in a higher chance of becoming distressed and feeling a sense of lack of control (Fisher, 1989).

\section{Stress and Coping}

The person-environment model is useful for understanding uprooting stress in first-year college transitions. According to Lazarus and Folkman's (1984) transactional theory of stress, when an individual encounters a stressful situation, it is necessary to appraise the potential threat posed by the situation and evaluate available resources, or coping strategies. Coping is defined as how an individual changes and/or cognitively structures stress in the personenvironment relationship (Lazarus \& Folkman, 1984). In the reaction process to stress, Rothabum, Weisz, and Snyder (1982) suggest that when a stress-provoking situation is encountered, individuals may exert primary control coping, aimed at taking control or action in the personenvironment relationship, or use secondary control coping, aimed at adjusting one's perception or interpretation of the person-environment relationship. In other words, primary coping is a behaviour oriented towards managing the stressor, while secondary coping is a cognitive change oriented towards reframing the stressor and fitting oneself into the environment (Skinner, Edge, Altman, \& Sherwood, 2003). Morling and Evered (2006) operationalised secondary coping as the strategy to adjust the self and accept the situation. In contrast, primary coping attempts to exert control of the situation. Both coping control strategies (primary and secondary) have been defined in terms of a fit-focused approach and are independent constructs (Morling \& Evered, 2006), meaning it is important to note that people can use either of these coping styles depending on which one fits the social context better.

\section{Goodness of Fit: Matching Control Strategy}

It should be obvious that the two coping strategies may not be equally effective in all situations. That is to say, primary coping is more applicable in situations where one has the opportunity and ability to change the circumstances (Zakowski, Hall, Klein, \& Baum, 2001), while secondary coping is better utilised when one has less control over their environment. According to the goodness-of-fit hypothesis, the correlation between one's appraisal of a situation and choice of a coping strategy will predict how well one adapts (Park, Folkman, \& Bostrom, 2001). Thus, the utilisation of a 'situationally' appropriate strategy has become extremely important to coping researchers (Zeidner \& Saklofske, 1996).

To date, many studies have fully supported the effectiveness of primary coping in high control situations, whereas secondary coping has been found to be maladaptive (Aldwin, 2007; Compas, Connor-Smith, Saltzman, Thomsen, \& Wadsworth, 2001). In low control situations, however, evidence as to the purported benefits of secondary coping is not so conclusive. Unfortunately, only a handful of studies have studied primary and secondary coping simultaneously (Forsythe \& Compas, 1987; Park et al., 2001; Zakowski et al., 2001). Nevertheless, as research has suggested secondary coping may be correlated with collectivistic cultural environments such as China (English, Zeng, \& Ma, 2015), Chinese participants may be better served by secondary coping than primary coping. Kuo's (2012) study supports this claim, arguing that a person's coping strategy must be understood within the frame of their social context. Secondary coping suits Asian cultures where interpersonal harmony and self-adjustment are valued (Kuo, 2012).

When applied appropriately, the utilisation of secondary coping resulted in lower levels of anxiety for Chinese participants who lacked control over their stressors (Cheng, Cheng, Hui, \& Lam, 1999). Alternatively, Chinese participants who deployed action-oriented strategies (primary coping) regardless of situational characteristics reported higher anxiety levels (Cheng, Cheung, Chio, \& Chan, 2013). Yet, secondary coping has been shown to differ within a cultural context and by the level of controllability. For example, Wang and Gan (2011) compared 
coping strategies in response to two events - a natural disaster and the Chinese college entrance exam (Gaokao), and found those who experienced a recent natural disaster reported more use of secondary coping, whereas the examination group (around 1,300 kilometres from the earthquake) reported more use of primary control engagement coping. Obviously, a natural disaster is an uncontrollable event that would most likely result in the utilisation of secondary coping to buffer the negative psychological effects. Due to the unpredictability of uprooting and leaving home behind for the first time, we argue for the benefits of secondary coping and harmful effects of primary coping on the stress-psychological adjustment relationship for college students in mainland China.

\section{The Chinese Setting}

Since the late 1970s, China's economic development has been led by millions of migrant workers who have helped transform villages into mega-cities (Fan, 2008). Internal migration, literally called 'floating population' in Chinese, is often characterised as rural residents (of interior provinces) moving to (coastal) cities for work. China has the largest internal migration in the world, with 221 million or almost $20 \%$ of its country migrating (Wang, Li, Stanton, \& Fang 2010). Since 2010, only 37\% of the more than 220 million migrants were moving for unskilled jobs, while pursuit of education rose sharply as a motivation for moving (Liang, Li, \& Ma, 2015). From the 2000 to 2010 censuses, higher education admissions (first-year students) increased from 2.21 million to over 6.5 million (as reported in Liang et al., 2015). This influx of students to college campuses represents a rapid increase in young Chinese leaving home for the first time (Lin et al., 2011).

While some research has examined this floating population, it has mainly centred on economic migrants, despite the fact that the trend of internal mobility has shifted to younger and educated 'peasants' seeking education opportunities and white collar jobs in coastal cities (Qiu, Xie, \& Zhou, 2004; Wang \& Fan, 2006). Unfortunately, no research has compared rural-to-urban versus urbanto-urban migration in either the context of economic or educational migration in China. Nevertheless, as the phenomenon of uprooting refers to leaving behind one's home and prior life, one would expect to find more uprooting stress for a rural-to-urban move than an urban-to-urban relocation.

Within the context of China, gender as a variable is too great for this article to adequately address. Historically, China has entrenched patriarchal values enshrined by the Confucian philosophy, best illustrated by the practice of foot binding, which did not die out until the early 20th century. Men and women were considered equal under communism, and Chairman Mao waws often quoted as saying 'women hold up half the sky'. Nevertheless, contemporary demographic data (118 men per 100 women births in 2010) suggests that favouritism towards boys per- sists. Interestingly, women are well represented on college campuses, making up over $50 \%$ of enrolment (Weng, Li, \& Foo 2016). In fact, the World Bank (2015) reported in 2013 that Chinese women were enrolled in higher education at a rate of 114 for every 100 men, and that this ratio appeared to be increasing dramatically since 2008 .

Research on gender differences in Chinese adolescence has revealed inconsistent findings regarding coping strategies and psychological symptoms. Some studies have reported more active (primary) coping for women (Herman-Stahl \& Petersen, 1996; Seiffge-Krenke, 1993). Others have found no gender differences (Chan, 1995; Kurdek, 1987), and some studies have reported that men use more problem-solving (primary) strategies compared to women (Chan, 1994; Seiffge-Krenke, 1993). One recent study by Yao et al. (2010) found Chinese male participants reported significantly higher mean scores on primary coping and secondary coping compared to Chinese females. In a review on homesickness, researchers previously suggested Chinese women experienced greater maladjustment due to leaving home (Scopelliti \& Tibero, 2010; Thruber, 2007), yet women were also reported to have lower homesickness. Crystal et al. (1994) found no gender differences for stress or depression in Taiwan, but women reported more somatic complaints compared to men. With this inconclusive stream of studies, it is difficult to make any predictions for gender differences, but it remains an important topic of study.

\section{Purpose of Study and Predictions}

The current study examined uprooting stress for educational internal migration in China by exploring the role of demographic variables on recently matriculated college students transitioning to a provincial capital city. We explored the role of hometown (urban vs. rural) and gender (female vs. male) due to Confucian values and the last several decades of social change in China (Bond, 2010). On the basis of the literature review of uprooting stress, coping control strategies, and adjustment for Chinese internal migrations, apart from planning exploratory tests of the demographic variables mentioned above, we formulated the following three main hypotheses $(\mathrm{H})$ :

H1: Students from a rural residence will report higher levels of uprooting stress (H1a) and anxiety (H1b) compared with students from an urban residence.

H2: Uprooting stress will lead to greater anxiety at time 2.

H3. Coping strategies will moderate uprooting stress on anxiety over time: (H3a) primary coping will exacerbate the negative effects of stress on anxiety at time 2 , while (H3b) secondary coping will buffer the stress and anxiety relationship. More secondary coping will lead to lower levels of anxiety.

\section{Methodology}

\section{Procedure}

At the beginning of the 2015 academic year, undergraduate students were recruited from three universities in eastern China to participate in a longitudinal study to examine the 
Table 1

Correlations, Means, and Reliabilities of Variables

\begin{tabular}{|c|c|c|c|c|c|c|c|c|c|c|c|}
\hline & 1 & 2 & 3 & 4 & 5 & 6 & 7 & M & SD & Cronbach's $\alpha$ & $\begin{array}{l}\text { Inter-item } \\
\text { correlations (total) }\end{array}$ \\
\hline 1.Anxietytime1 & - & & & & & & & 2.63 & 1.00 & .76 & $.28-.61(.27)$ \\
\hline 2.Uprooting stress time1 & $.48^{* * *}$ & - & & & & & & 2.32 & 0.74 & .68 & $.40-.63(.36)$ \\
\hline 3.Primary copingtime1 & -.04 & -.10 & - & & & & & 3.24 & 0.41 & .76 & $.35-.55(.30)$ \\
\hline 4. Secondary copingtime1 & -.08 & -.10 & $.56 * * *$ & - & & & & 3.40 & 0.41 & .70 & $.20-.52(.24)$ \\
\hline 5. Anxiety time2 & $.52^{* * *}$ & $.24^{* *}$ & .01 & -.06 & - & & & 2.72 & 0.98 & .80 & $.24-.69(.36)$ \\
\hline 6. Age & -.02 & .03 & -.03 & -.11 & -.08 & - & & 20.30 & 2.02 & & \\
\hline 7. Time at university (in days) & .07 & .05 & $.19^{* *}$ & $.14^{*}$ & -.04 & .10 & - & 151.91 & 580.42 & & \\
\hline
\end{tabular}

Note: Correlations: ${ }^{+} .10,{ }^{*} p<.05,{ }^{* *} p<.01,{ }^{* * *} p<.001$. Total means are reported. $N=169$.

impact of uprooting stress on their transition to the first year in college. Three months later, the same students were given a follow-up questionnaire. All participation was voluntary and had no impact on their grades or standing in the university. Participants provided a code (birth month, father's birthday, and mother's maiden name) that was used to match participants across time 1 and time 2, but were otherwise granted anonymity.

\section{Sample}

Originally, 202 Chinese students with ages ranging from 18 to $28(M=20.8, S D=2.02)$ agreed to participate in the present study. However, only 169 (72\% female) students completed both time waves (90-day time lag) and were used in the present analyses; $52 \%$ of participants were from the countryside and had been living on campus at the university for less than 6 months.

In longitudinal analyses, attrition is always a major concern as participants may drop out for unknown reasons. The data were subjected to $t$-test analyses to examine the attrition rate by tested variables. Two hundred and two participants completed the first questionnaire, and 169 were matched at time 2 for a reasonably low attrition rate of $16 \%$. Between groups $t$ tests revealed two significant differences with those completing both questionnaires reporting higher anxiety, $M=2.75(S D=.96)$ versus $M=2.32(S D=.78) ; t(200)=2.48, p=.04$, Cohen's $d=.35$, and being older, $M=20.30(S D=2.02)$ versus $M=19.35(S D=1.84) ; t(200)=2.69, p=.001$, Cohen's $d=.39$, than those who only completed questionnaire at time 1 . No other differences were found in attrition analyses.

\section{Materials}

The measurements used in the present study were adopted from Szabo et al. (2016) and are explained below.

Psychological adjustment. The anxiety measure was drawn from Goldberg and Hiller's (1979) General Health Questionnaire's (GHQ-28) anxiety subscale, which has been used in several studies measuring adjustment (Nakagawa \& Daibo, 1985). The measure asked individuals to respond to how they had been feeling in the past 2 weeks (e.g., 'I have been feeling constantly under strain' and 'I have been under pressure'). A 7-point anchor Likert scale $(1=$ never to $7=$ always $)$ was used to indicate the level of anxiety perceived by participants. The internal reliability was .76 at time 1 and .80 at time 2 .

Uprooting Stress. Uprooting stress, as first defined in Szabo et al. (2016), included four items measuring the intensity of the stress from 'feeling separated from friends and family from back home', 'leaving something of importance behind', 'saying goodbye to people from back home', and 'deciding what to bring to the new place of residence'. Participants were asked 'In the last month, how often have you felt stressed from ...?' Each question was anchored on a 7 -point Likert scale $(1=$ never to $7=$ always $)$ and was used to indicate the level of uprooting stress participants had as a result of leaving home. The Cronbach's alpha was slightly below the recommended threshold of .70, yet the inter-item and item-total correlations met the threshold for good internal consistency (Table 1).

Primary and secondary coping. Primary and secondary coping were measured using the COPE Inventory (Carver, Scheier, \& Weintraub, 1989). The four coping subscales (i.e., active coping, planning, positive reinterpretation, and acceptance) were composed of four items each. Participants gave responses to statements such as 'I take direct action to get around the problem' (active coping), 'I make a plan of action' (planning), 'I look for something good in what is happening' (positive reinterpretation), and 'I accept the reality of the fact that it happened' (acceptance) on a 4-point scale anchored by $1=$ don't do this at all and $4=$ do this a lot. Primary coping was measured by eight items consisting of active and planning coping. Secondary coping was measured by eight items and consisted of positive reinterpretation and acceptance dimensions. Both primary and secondary coping demonstrated good internal consistency (Table 1).

\section{Data Analyses Plan}

The preliminary analyses of the present longitudinal study consisted of zero-order correlations conducted to examine basic relationships among age, length of time at university, and core variables. We then tested for group differences using a multivariate analysis of variance (MANOVA) to investigate the rural-to-urban migration hypothesis and 
Table 2

Testing Multivariate Analyses by Hometown and Gender on Adjustment Variables

\begin{tabular}{|c|c|c|c|c|c|c|c|}
\hline & \multicolumn{3}{|c|}{ Residence type } & \multicolumn{3}{|c|}{ Gender } & \multirow{2}{*}{$\begin{array}{l}\begin{array}{l}\text { Interaction effect } \\
(\text { Grew up } \times \text { Gender })\end{array} \\
F\left(\eta^{2}\right)\end{array}$} \\
\hline & Rural & Urban & $F\left(\eta^{2}\right)$ & Female & Male & $F\left(\eta^{2}\right)$ & \\
\hline 1.Anxiety time1 & 2.74 & 2.60 & $.51(.00)$ & 2.46 & 2.89 & $4.53^{*}(.03)$ & $3.68^{+}(.02)$ \\
\hline 2.Uprooting stresstime1 & 2.54 & 2.25 & $4.03 *(.02)$ & 2.22 & 2.57 & $6.32 * *(.04)$ & $2.87^{+}(.02)$ \\
\hline 3. Anxietytime2 & 2.79 & 2.72 & $.12(.00)$ & 2.50 & 3.00 & $6.34 * *(.04)$ & $.62(.00)$ \\
\hline
\end{tabular}

Note: Residence type: $0=$ rural, $1=$ urban; Gender: $0=$ female, $1=$ male.

$+.10,{ }^{*} p<.05,{ }^{* *} p<.01,{ }^{* * *} p<.001$.

\section{Table 3}

Testing Multivariate Analyses By Hometown and Gender on Coping Styles

\begin{tabular}{|c|c|c|c|c|c|c|c|}
\hline & \multicolumn{3}{|c|}{ Residence type } & \multicolumn{3}{|c|}{ Gender } & \multirow{2}{*}{$\begin{array}{l}\text { Interaction effect } \\
\text { (Grew up } \times \text { Gender) } \\
F\left(\eta^{2}\right)\end{array}$} \\
\hline & Rural & Urban & $F\left(\eta^{2}\right)$ & Female & Male & $F\left(\eta^{2}\right)$ & \\
\hline Primary coping time1 $_{1}$ & 3.23 & 3.22 & $.03(.00)$ & 3.29 & 3.17 & $2.25(.01)$ & $.60(.00)$ \\
\hline Secondary coping time1 & 3.41 & 3.38 & $.12(.00)$ & 3.42 & 3.38 & $.20(.00)$ & $.02(.00)$ \\
\hline
\end{tabular}

Note: Residence type: $0=$ rural, $1=$ urban; Gender: $0=$ female, $1=$ male.

$+.10 *{ }^{*} p<.05 * * p<.01 * * * p<.001$

effects of gender. Finally, to test the goodness-of-fit hypothesis for effects of uprooting stress and coping on anxiety over time, a hierarchical regression analysis was conducted. In the regression model, step 1 included the longitudinal residual, anxiety timel. Step 2 included control variables (gender, residence type, time at university, and age). Uprooting stress timel $_{\text {was }}$ entered in step 3. In step 4, our moderators (primary and secondary coping) were added, and finally, the two interactions effects were included (uprooting stress $\times$ primary coping and uprooting stress $\times$ secondary coping) in step 5 .

\section{Data Analysis}

\section{Preliminary Analyses}

Bivariate correlations (see Table 1) revealed a medium to strong positive association between anxiety timel $_{\text {and }}$ and anxietytime2 $(r=.52, p=.001)$ as well as between primarytimel and secondary coping strategies at time 1 $(r=.56, p=.001)$. Uprooting stress timel $_{\text {was }}$ wasitively correlated with anxiety time1 $(r=.48, p=.001)$ and correlated with anxiety $y_{\text {time }}(r=.24, p=.01)$. Time at university was correlated with primary coping timel $(r=.19, p=.02)$ and secondary coping $g_{\text {timel }}(r=.14, p=.03)$. No other correlations were significant.

A two-by-two MANOVA was conducted to examine mean group differences on anxiety $y_{\text {timel }}$, uprooting stress $_{\text {timel }}$, and anxiety time2. This analysis allowed us to examine group differences and the possibility of an interaction effect (residence type $\times$ gender).

The results indicated a significant effect by gender, Wilk's $\lambda=.95, F(3,167)=1.96, p=.01 \eta^{2}=0.10$. We found a marginally significant interaction for residence type by gender, Wilk's $\lambda=0.92, F(3,167)=1.05, p=$ $.10, \eta^{2}=0.09$. Surprisingly, no significant main effect was found for residence type, $F(3,167)<1.00$, ns. All results are shown in Table 2.

Between-group mean analyses showed significant differences. Females reported significantly less anxiety timel $_{\text {, }}$ $M=2.46, S E=.13$, anxiety $y_{\text {time2 }}, M=2.50, S E=.12$, and uprooting stress, $M=2.22, S E=.09$, compared with males, anxiety $_{\text {time } 1}, M=2.89, S E=.16, F(1,167)=4.53, p=.03$, $\eta^{2}=.03$; anxiety time2 $_{2}, M=2.99, S E=.15, F(1,167)=6.34$, $p=.01, \eta^{2}=.04$; uprooting stress: $M=2.57, S E=.11, F(1$, 167) $=6.32, p=.01, \eta^{2}=.04$.

A second MANOVA (residence type $\times$ gender) was conducted to examine mean group differences by coping styles (primary coping time1 $_{\text {, and secondary coping }}$ timel ). The results indicated no significant main effect by gender, $F(2,168)<1.00, n s$; no effect was found for residence type, $F(2,168)<1.00, n s$; and no interaction residence type by gender was found, $F(2,168)<1.00$, ns. Between-group mean analyses are shown in Table 3.

Given that a statistically significant effect for resident type by gender interaction was not found $(p=.10)$, hypotheses $1 \mathrm{a}$ and $1 \mathrm{~b}$ were not confirmed. While no predictions were made for gender differences, analyses show females reported lower anxiety and uprooting stress compared to males. No significant differences were reported in coping styles by gender or type of residence.

\section{Testing the Interaction Effect on Anxiety Over Time}

To test the main effect for uprooting stress (H2) and interaction effects ( $\mathrm{H} 3, \mathrm{H} 3 \mathrm{a}, \mathrm{H} 3 \mathrm{~b})$, a hierarchical linear regression model was conducted (as in Szabo et al., 2016). In step 1, anxiety timel $_{\text {was }}$ residualised on the anxiety time2, $_{\text {, }}$ thus predicting which variables from time 1 (demographic variables, uprooting stress, and coping strategies) lead to a change in anxiety (Jose \& Huntsinger, 2005). The entire model revealed in step 5 explained $40 \%$ of the variance and 
Table 4

Hierarchical Regression Analysis Predicting Anxiety Over Time

\begin{tabular}{|c|c|c|c|}
\hline & Beta & $R^{2} / \Delta R^{2}$ & $\Delta F(d f s)$ \\
\hline Step 1 & & $.33 /-$ & $83.71(1,168)$ \\
\hline Anxiety time 1 & $.51^{* * *}$ & & \\
\hline Step 2 & & $.36 / .03^{*}$ & $1.62(4,164)$ \\
\hline Anxiety time 1 & $.59 * * *$ & & \\
\hline Residence type & -.03 & & \\
\hline Gender & $.15^{*}$ & & \\
\hline Time at university & -.06 & & \\
\hline Age & .02 & & \\
\hline Step 3 & & $.36 / .00$ & $.13(1,163)$ \\
\hline Anxiety time 1 & $.58 * * *$ & & \\
\hline Residence type & .02 & & \\
\hline Gender & $.16^{* *}$ & & \\
\hline Time at university & .00 & & \\
\hline Uprooting stress & .03 & & \\
\hline Step 4 & & $.37 / .01$ & $.99(2,161)$ \\
\hline Anxiety time 1 & $.58^{* * *}$ & & \\
\hline Residence type & .02 & & \\
\hline Gender & $.17^{* *}$ & & \\
\hline Time at university & -.01 & & \\
\hline Uprooting stress & .02 & & \\
\hline Primary coping & .10 & & \\
\hline Secondary coping & -.08 & & \\
\hline Step 5 & & $.40 / .03^{*}$ & $3.87(2,159)$ \\
\hline Anxiety time 1 & $.57^{* * *}$ & & \\
\hline Residence type & .01 & & \\
\hline Gender & $.15^{*}$ & & \\
\hline Time at university & -.02 & & \\
\hline Uprooting stress & .02 & & \\
\hline Primary coping & $.12^{+}$ & & \\
\hline Secondary coping & -.10 & & \\
\hline Uprooting stress $\times$ Primary & $.20^{* *}$ & & \\
\hline Uprooting stress $\times$ Secondary & -.05 & & \\
\hline
\end{tabular}

Note: Dependent variable was Anxiety time 2. Residence type dummy coded: $0=$ rural, $1=$ urban; Gender: $0=$ female, $1=$ male. ${ }^{+} p<.10 ;{ }^{*} p \leq .05{ }^{* *} p \leq .001$.

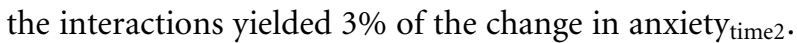
In step 2, control variables accounted for $3 \%$ of change in variance of the predictor. Gender was a positive and significant predictor $(\beta=.15, p=.01)$, indicating that males experienced more anxiety over time. Uprooting stress did not exert a main effect on anxiety; instead, it interacted with primary coping $(\beta=.20, p=.01)$. Secondary coping exerted no significant effect in the model. Table 4 shows the hierarchical linear regression model.

The significant moderator (uprooting stress $\times$ primary coping) was further subjected to simple slope analysis and was graphed for easier interpretation (as suggested by Cohen, Cohen, \& Aiken, 1983). In Figure 1, we can see how primary coping functions as a moderator. According to simple slopes analyses, when students use low levels of primary coping, uprooting stress is negatively related to anxiety over time, $t$ low $(167)=-1.68 p=.09$, Cohens $d=.26$. When students use high levels of primary coping, $t$ high $(167)=-2.34, p=.02$, Cohen's $d=.36$, uprooting stress is positively related to anxiety over time. Uprooting is positively or negatively related with anxiety depending on the level of primary coping. In addition, this effect is only present when primary coping is taken into account. In other words, Chinese freshmen who utilise high levels of primary coping for managing an uncontrollable stressor, such as uprooting stress, also experience more anxiety over time.

In reviewing the main hypotheses, although uprooting stress is correlated with anxiety tim2 $_{2}$, it failed to predict a change in anxiety in the regression model (H2). Hypothesis 3 was partially confirmed: primary coping interacted with uprooting stress ( $\mathrm{H} 3 \mathrm{a})$, functioning as an amplifier, but secondary coping did not interact with uprooting stress, thus rejecting $\mathrm{H} 3 \mathrm{~b}$.

\section{Discussion}

The main aim of the present study was to examine an emerging type of educational sojourner in a rapidly changing Chinese society, together with uprooting stress, as a potentially meaningful paradigm for understanding the adaptation process of leaving one's home behind. To further build upon the research framework, we included gender differences and residence type, categorised as urban versus rural. Our longitudinal study further supported the detrimental effects of employing primary coping strategies when dealing with uncontrollable stressors, such as uprooting stress. Below we will discuss the results in detail.

First, as expected, we found a positive correlation between uprooting stress and anxiety. In line with the goodness-of-fit hypothesis, we found primary coping was not successful in reducing maladaptation, but instead amplified the negative impact of stress on anxiety. This interaction effect supports Szabo et al. (2016).

Second, our findings found no main effect or interaction effect in secondary coping control, which further contributes to the mixed findings regarding secondary coping (Morling \& Evered, 2007). In fact, some recent research has found that Asians may prefer to use a primary coping control as opposed to secondary coping (Sawaumi, Yamaguchi, Park, \& Robinson, 2015). A recent study by English et al. (2015), found that secondary coping was adaptive for both Westerners and (non-Chinese) Asians living in China. Further attention needs to be given to secondary coping regarding its benefits for situational stress and the impact of environment on coping styles. Because primary coping exacerbated the negative effects of uprooting stress on anxiety and secondary coping had no significant effect, it may be necessary to look outside of intrapersonal coping strategies for viable strategies for first-year college students in China. Brewin et al. (1989) found that students who discussed their feelings of homesickness were more likely to report depression, as there was a need for affiliation. Yet more recent studies have found certain types of social support (emotional and instrumental) to be beneficial. For example, Daugherty and Lane (1999) found that establishing social bonds and friendship support networks with college peers and academic advisors during the first-year transition improved academic performance and psychological wellbeing. Having a high perception of availability for social support friends and family have also 


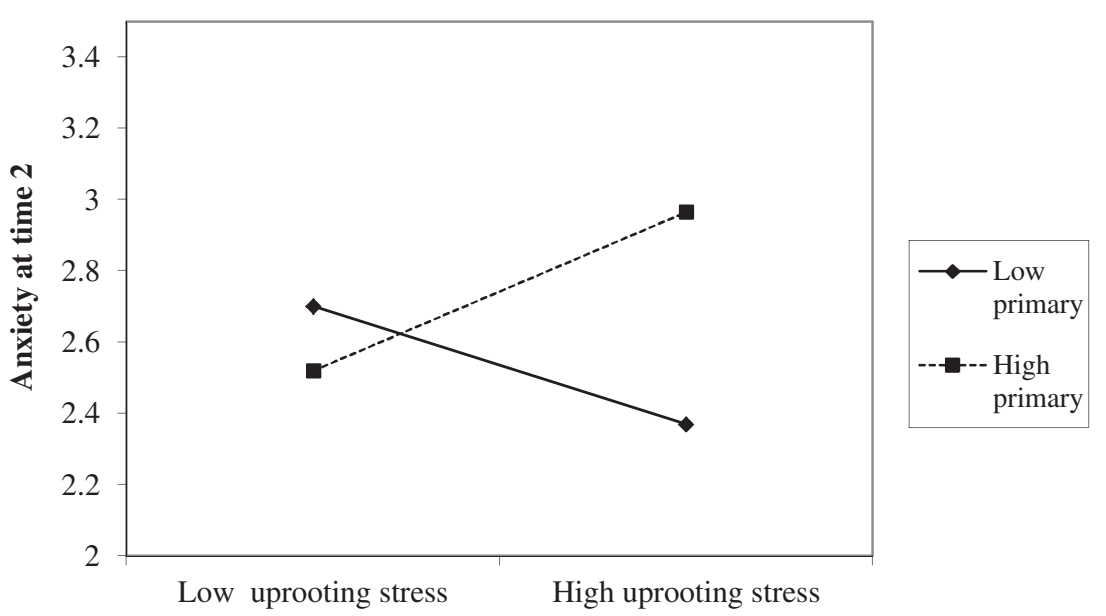

Figure 1

Moderation effect of primary coping time 1 on uprooting stresstime1 and anxietytime2.

been found to alleviate homesickness (Baqutayan, 2011) We believe that social support, especially within the collective society of China, might play an vital part in alleviating symptoms of stress particularly uprooting stress. Unfortunately, we did not examine the role of social support in dealing with uprooting stress, but it should be considered in future research.

Major gender differences were found. Females were better adapted, as they reported less anxiety and stress despite slightly more utilisation of primary coping. We attributed this finding to a shift in gender differences and social norms for Chinese males and females. Lee and Padilla (2014) found that Asian (Korean) males reported greater stress, noting language and cultural difficulties during their study in the United States. While our findings are interesting, we are cautious about their interpretation and suggest further investigation, as generalisation of gender differences is often problematic. Future research is necessary to disentangle gender differences in a modern Chinese context.

We found one group difference based on whether a participant's hometown was rural or urban, that uprooting stress was greater for those from the countryside. Though previous researchers have found differences between rural and urban migration (Du et al., 2014; Chen, Wang, Li, \& Liu, 2014), our study failed to find differences in coping strategies or anxiety. Given that our sample was a homogenous group of college students, it could be argued that for Chinese youth today, the rural-urban gap is closing due to exposure to mass media. Rosen (2009) observed that media was second only to the Chinese economy in terms of creating a significant cross-generational shift of values. Chinese people born after 1980 have been found to identify more with Western values and culture (Rosen, 2009). Furthermore, travel, both domestic and international, has become increasingly more common in China (Fish, 2015), and the present study failed to account for that.

\section{Cultural Differences Within a Chinese Context}

China is a large, multi-ethnic (at least 90\% Han Chinese) country, and it would be a mistake to overgeneralise any similar transition to college for all Chinese students. Talhelm et al. (2014) argued that cognitive differences (i.e., holistic thinking) can be found among different regions in China based on the agricultural suitability for growing rice or wheat; while Van de Vliet, Yang, Wang, and Ren (2013) suggested that the interaction between climate and wealth foster collectivism. Climate and agriculture are obviously correlated, as are urban-rural and economic development. However, as applied to the present study, the key idea is that while our entire sample is leaving their hometown to attend college, we posited that a transition from a rural environment to an urban one would be more stressful than an urban-to-urban transition because of the implicit cultural distance and/or a more acute sense of uprooting. Unfortunately, the findings failed to confirm our expectation.

We suspect that the effect of secondary coping was confounded by regional differences, as the majority of the participants $(85 \%)$ came from a northern province that can be considered a 'wheat' province (as defined by Talhelm et al., 2014). Wheat agriculture fosters a more independent (analytic thought) and individualistic orientation, which could be linked with a context where primary coping styles are more effective. Migrating from a wheat province to a rice province (more holistic and possibly more secondary) could result in coping styles that are (mal-)adaptive. Further research needs to be done to explore coping styles and adaptation trajectories based on these within-culture differences of collectivism versus individualism - for example, comparing the relationship among uprooting stress, anxiety, and coping strategies of northern Chinese moving to southern universities and vice versa. This is especially important, as China's internal migration is also largely interprovincial (Fan, 2008). 


\section{Limitations and Conclusions}

It is important to note several limitations of this study, and given the nature of our sample and methodology, it is of extreme importance to caution the interpretation of the reported findings. First, we relied on self-reported measures to assess uprooting stress, coping controls and anxiety, which may lead to measurement bias, though this has been a major method for acculturation research (Berry, 2006). The present study also failed to examine the university site effect, as participants attended three different university campuses. In order to fully unpack the differences and understand the role of coping, it would be best for the researchers to examine regional differences more appropriately and systematically (north-south differences, east-west differences, and rural vs. urban differences) as suggested by Ruan, Xie, and Zhang (2015). Finally, by only studying educational migration, we cannot extend the results to build on the literature concerning the more prevalent economic migration in China.

Despite these limitations, the present longitudinal study replicated findings from Szabo et al. (2016), which examined key demographic variables that undergird major aspects of Chinese society, and further advanced coping research to examine the understanding of coping control in both reducing uprooting stress and other types of stress during a college transition. In light of the growing trend of internal and international migration, we examined an under-researched group of educational migrants and answered the call for coping research outside of a Western context (Kuo, 2013).

The present study has clear implications for higher education in China as over 28 million students attend college each year. University students often seek out help due to homesickness or depression. As the present study suggests that primary coping leads to more maladaptation, practitioners at universities should pursue alternative tracks, such as cognitive behavioral therapy or directing students to support groups. Considering the prevalence of movement of people across international and intranational borders, the results of this study and other studies of coping with stress indicate that researchers and practitioners need to further understand coping and its relationship to transitional processes for successful and positive outcomes for migrants.

\section{Conflict of Interest}

None.

\section{Ethical Approval}

This research project was approved by the Human Ethics Committee of the Department of Psychology and Behavioral Sciences at Zhejiang University, Hangzhou, China. Informed consent was obtained from all individual participants in this study.

\section{Acknowledgments}

The authors are extremely grateful for the constructive comments on the earlier versions of this article from two anonymous reviewers. Authors would also like to thank Greg DuBois for his helpful comments and suggestions.

\section{Endnote}

1 While Demes and Geeraert's (2015) research study focused on volunteer students placed around the world. Students also lived with a homestay family and studied at local high schools. Their findings pinpoint the uprooting stress and coping relationship in cross-cultural transitions.

\section{References}

Aldwin, C.M. (2007). Stress, coping, and development: An integrative perspective. New York, NY: Guilford Press.

Baqutayan, S. (2011). Stress and social support. Indian Journal of Psychological Medicine, 33, 29-34.

Berry, J.W. (2006). Acculturative stress. In P.T.P. Wong \& L.C.J. Wong (Eds.), Handbook of multicultural perspectives on stress and coping (pp. 287-298). Dallas, TX: Springer. https:// doi.org/10.1007/0-387-26238-5_12

Bond, M.H. (2010). The Oxford handbook of Chinese psychology. Oxford, UK: Oxford University Press. https:// doi.org/10.1093/oxfordhb/9780199541850.001.0001

Brown, R.H. (1980). Identity, politics, planning: On some uses of knowledge in coping with social change. In G.V. Coehlo \& P.I. Ahmed (Eds.), Uprooting and development: Dilemmas of coping with modernization (pp. 41-66). New York, NY: Springer US. https://doi.doi.org/ 10.1007/978-1-4684-3794-2_3

Brewin, C.R., Furnham, A., \& Howes, M. (1989). Demographic and psychological determinants of homesickness and confinding among students. British Journal of Psychology, 80, 467-477. https://doi.doi.org/ 10.1111/j.2044-8295.1989.tb02336.x

Carden, A., \& Feicht, R. (1991). Homesickness among American and Turkish college students. Journal of Cross Cultural Psychology, 22, 418-428.

Carver, C.S., Scheier, M.F., \& Weintraub, J.K. (1989). Assessing coping strategies: a theoretically based approach. Journal of Personality and Social Psychology, 56, 267-283. https://doi.doi.org/10.1037/0022-3514.56.2.267

Chan, D.W. (1994). The Chinese Ways of Coping Questionnaire: Assessing coping in secondary school teachers and students in Hong Kong. Psychological Assessment, 6, 108-116.

Chan, D.W. (1995). Depressive symptoms and coping strategies among Chinese adolescents in Hong Kong. Journal of Youth and Adolescence, 24, 267-279.

Chen, X., Wang, L., Li, D., \& Liu, J. (2014). Loneliness in Chinese children across contexts. Developmental Psychology, 50, 2324-2333. https://doi.doi.org/10.1037/a0037689

Cheng, C., Cheung, S.F., Chio, J.H.M., \& Chan, M.P.S. (2013). Cultural meaning of perceived control: A meta-analysis of locus of control and psychological symptoms across $18 \mathrm{cul}$ tural regions. Psychological Bulletin, 139, 152. 
Cheng, C., Hui, W.M., \& Lam, S.K. (1999). Coping style of individuals with functional dyspepsia. Psychosomatic Medicine, 61, 789-795.

Cohen, J., Cohen, P., West, S.G., \& Aiken, L.S. (1983). Applied multiple regression correlation for the behavioral sciences. Hillsdale, NJ: Erlbaum.

Compas, B.E., Connor-Smith, J.K., Saltzman, H., Thomsen, A.H., \& Wadsworth, M.E. (2001). Coping with stress during childhood and adolescence: problems, progress, and potential in theory and research. Psychological Bulletin, 127, 87-127. https://doi.doi.org/10.1037/0033-2909.127.1. 87

Crystal, D.S., Chen, C., Fuligni, A.J., Stevenson, H.W., Hsu, C.C., Ko, H.J., ... Kimura, S. (1994). Psychological maladjustment and academic achievement: A cross-cultural study of Japanese, Chinese, and American high school students. Child Development, 65, 738-753.

Daugherty, T.K., \& Lane, E.J. (1999). A longitudinal study of academic and social predictors of college attrition. Social Behavior and Personality, 27, 355-361.

Demes, K.A., \& Geeraert, N. (2015). The highs and lows of a cultural transition: A longitudinal analysis of sojourner stress and adaptation across 50 countries. Journal of Personality and Social Psychology, 109, 316.

Du, H., Li, X., Lin, D., Tam, C (2014) Hopelessness, individualism, collectivism, and substance use among young rural-tourban migrants in China. Health Psychology and Behavioral Medicine, 21, 211-220. doi:10.1080/21642850.2014.888656

English, A., Zeng, Z., \& Ma, J. (2015). The stress of studying in China: Primary and secondary coping interaction effect. SpringerPlus 4, 755. doi:10.1186/s400064-015-1540-3

Fan, C.C. (2008). China on the move: Migration, the state, and the household. The China Quarterly, 196, 924-956.

Fish, E. (2015). China's millennials: The want generation. Lanham, MD: Rowman \& Littlefield Publishers.

Fisher, S. (1989). Homesickness, cognition, and health. London: Erlbaum.

Fisher, S., \& Hood, B. (1988). Vulnerability factors in the transition to university: Self-reported mobility history and sex differences as factors in psychological disturbance. British Journal of Psychology, 79, 309-320.

Forsythe, C.J., \& Compas, B.E. (1987). Interaction of cognitive appraisals of stressful events and coping: Testing the goodness of fit hypothesis. Cognitive Therapy and Research, 11, 473-485. https://doi.doi.org/10.1007/BF01175357

Goldberg, D.P., \& Hillier, V.F. (1979). A scaled version of the General Health Questionnaire. Psychological Medicine, 9, 139145. https://doi.doi.org/10.1017/S0033291700021644

Herman-Stahl, M., \& Petersen, A.C. (1996). The protective role of coping and social resources for depressive symptoms among young adolescents. Journal of Youth and Adolescence, $25,733-753$.

Hinderlie, H.H., \& Kenny, M. (2002). Attachment, social support, and college adjustment among Black students at predominantly White universities. Journal of College Student Development, 43, 327-340.
Jose, P.E. \& Huntsinger, C.S. (2005) Moderation and mediation effects of coping by Chinese American and European American adolescents. The Journal of Genetic Psychology: Research and Theory on Human Development, 166, 16-44. https://doi.doi.org/10.3200/GNTP.166.1.16-44

Kuo, B.C. (2013). Collectivism and coping: Current theories, evidence, and measurements of collective coping. International Journal of Psychology, 48, 374-388. $\quad$ https://doi.doi.org/10.1080/00207594.2011. 640681

Kurdek, L.A. (1987). Gender differences in the psychological symptomatology and coping strategies of young adolescents. The Journal of Early Adolescence, 7, 395-410.

Lazarus, R.S., \& Folkman, S. (1984). Stress, appraisal, and coping. New York, NY: Springer.

Morling, B., \& Evered, S. (2006). Secondary control reviewed and defined. Psychological Bulletin, 132, 269296.

Morling, B., \& Evered, S. (2007). The construct formerly known as secondary control: Reply to Skinner (2007). Psychological Bulletin, 133, 917-919.

Nakagawa, Y., \& Daibo, I. (1985). Japanese version of the General Health Questionnaire. Tokyo, Japan: Nihon Bunka Kagakusha.

Lee, D.S., \& Padilla, A.M. (2014). Acculturative stress and coping: Gender differences among Korean and Korean American university students. Journal of College Student Development, $55,243-262$.

Liang, Z., Li, Z., \& Ma, Z. (2014). Changing patterns of the floating population in China, 2000-2010. Population and Development Review, 40, 695-716. https://doi.doi.org/ 10.1111/j.1728-4457.2014.00007.x

Lin, D., Li, X., Wang, B., Hong, Y., Fang, X., Qin, X., \& Stanton, B. (2011). Discrimination, perceived social inequity, and mental health among rural-to-urban migrants in China. Community Mental Health Journal, 47, 171-180. https://doi.doi.org/10.1007/s10597-009-9278-4

Park, C.L., Folkman, S., \& Bostrom, A. (2001). Appraisals of controllability and coping in caregivers and HIV+ men: Testing the goodness-of-fit hypothesis. Journal of Consulting and Clinical Psychology, 69, 481-488.

Poyrazli, S., \& Lopez, M.D. (2007). An exploratory study of perceived discrimination and homesickness: A comparison of international students and American students. The Journal of Psychology, 141, 263-280.

Qiu, Z.Y., Xie, P., and Zhou, F.L., (2004). Renkou liudong dui jingji shehui fazhan di yingxiang [Impacts of migration on socioeconomic development]. Renkou Xuekan [Population Journal], 2004(1), 47-52.

Rosen, S. (2009). Contemporary Chinese youth and the state. The Journal of Asian Studies, 68, 359. https://doi.doi.org/ $10.1017 /$ S0021911809000631

Rothbaum, F., Weisz, J.R., \& Snyder, S.S. (1982). Changing the world and changing the self. Journal of Personality and Social Psychology, 42, 5-37. https://doi.doi.org/ 10.1037/0022-3514.42.1.5 
Ruan, J., Xie, Z., \& Zhang, X. (2015). Does rice farming shape individualism and innovation? Food Policy, 56, 51-58. https://doi.doi.org/10.1016/j.foodpol.2015.07.010

Sawaumi, T., Yamaguchi, S., Park, J., \& Robinson, A.R. (2015). Japanese control strategies regulated by urgency and interpersonal harmony evidence based on extended conceptual framework. Journal of Cross-Cultural Psychology, 46, 252268. https://doi.doi.org/10.1177/0022022114563749

Scharp, K.M., Paxman, C.G., \& Thomas, L.J. (2016). 'I want to go home' homesickness experiences and social-support-seeking practices. Environment and Behavior, 48, 1175-1197.

Scopelliti, M., \& Tiberio, L. (2010). Homesickness in university students: The role of multiple place attachment. Environment and Behavior, 42, 335-350.

Seiffge-Krenke, I. (1993). Coping behavior in normal and clinical samples: More similarities than differences? Journal of Adolescence, 16, 285-303.

Skinner, E.A., Edge, K., Altman, J., \& Sherwood, H. (2003). Searching for the structure of coping: A review and critique of category systems for classifying ways of coping. Psychological Bulletin, 129, 216. https://doi.doi.org/ 10.1037/0033-2909.129.2.216

Stroebe, M., Vliet, T., Hewstone, M., \& Willis, H. (2002). Homesickness among students in two cultures: Antecedents and consequences. British Journal of Psychology, 93, 147-168.

Sun, J. (2015). Homesick at college: A predictive model for first-year first-time students. Graduate Theses and Dissertations Paper No. 14890. Retrieved from http://lib.dr. iastate.edu/etd/14890

Szabo, A., Ward, C., \& Jose, P.E. (2016). Uprooting stress, coping, and anxiety: A longitudinal study of international students. International Journal of Stress Management, 23, 190-208.

Talhelm, T., Zhang, X., Oishi, S., Shimin, C., Duan, D., Lan, X., \& Kitayama, S. (2014). Large-scale psychological differences within China explained by rice versus wheat agriculture. Science, 344, 603-608. https://doi.doi.org/ $10.1126 /$ science. 1246850

Tao, S., Dong, Q., Pratt, M.W., Hunsberger, B., \& Pancer, S.M. (2000). Social support relations to coping and adjustment during the transition to university in the People's Republic of China. Journal of Adolescent Research, 15, 123-144.

Thurber, C.A., \& Walton, E. (2007). Preventing and treating homesickness. Pediatrics, 119, 192-201.

Thurber, C.A., \& Weisz, J.R. (1997). Describing boys' coping with homesickness using a two-process model of coping. Anxiety, Stress and Coping, 10, 181-202. https://doi.doi.org/ $10.1080 / 10615809708249300$
Tognoli, J. (2003). Leaving home: Homesickness, place attachment, and transition among residential college students. Journal of College Student Psychotherapy, 18, 35-48.

Urquhart, B.A., \& Pooley, J. (2007). The transition experience of Australian students to university: The importance of social support. The Australian Community Psychologist, 19, 78-91.

Van de Vliert, E., Yang, H., Wang, Y., \& Ren, X.P. (2013). Climato-economic imprints on Chinese collectivism. Journal of Cross-Cultural Psychology, 44, 589-605. https://doi.doi.org/10.1177/0022022112463605

Wang, W.F, and Fan, C. (2006). Success or failure: Selectivity and reasons of return migration in Sichuan and Anhui, China. Environment and Planning, 38, 939-958. https://doi.doi.org/10.1068/a37428

Wang, Z., \& Gan, Y. (2011). Coping mediates between social support, neuroticism, and depression after earthquake and examination stress among adolescents. Anxiety, Stress, \& Coping, 24, 343-358.

Wang, B., Li, X., Stanton, B., \& Fang, X. (2010). The influence of social stigma and discriminatory experience on psychological distress and quality of life among rural-to-urban migrants in China. Social Science \& Medicine, 71, 84-92. https://doi.doi.org/10.1016/j.socscimed.2010.03.021

Ward, C. (2001). The A, B, Cs of acculturation. In D. Matsumoto (Ed.), The handbook of culture and psychology (pp. 411-445). Oxford, UK: Oxford University Press.

Weng, Y., Li, M., \& Foo, C.T. (2016). Education inside China: A longitudinal (1989-2011) analysis. Chinese Management Studies, 10, 217-241.

The World Bank Group. (2015). Ratio of female to male tertiary enrollment (\%) [Data table]. Retrieved from http://data.worldbank.org/indicator/SE.ENR.TERT.FM.ZS

Yao, S., Xiao, J., Zhu, X., Zhang, C., Auerbach, R.P., McWhinnie, C.M., ... Wang, C. (2010). Coping and involuntary responses to stress in Chinese university students: Psychometric properties of the Responses to Stress Questionnaire. Journal of Personality Assessment, 92, 356-361. https://doi.doi.org/10.1080/00223891.2010.482015

Zakowski, S.G., Hall, M.H., Klein, L.C., \& Baum, A. (2001). Appraised control, coping, and stress in a community sample: A test of the goodness-of-fit hypothesis. Annals of Behavioral Medicine, 23, 158-165. https://doi.doi.org/ 10.1207/S15324796ABM2303_3

Zeidner, M., \& Saklofske, D. (1996). Adaptive and mal-adaptive coping. In M. Zeidner \& N.S. Endler (Eds.), Handbook of coping: Theory, research, applications (pp. 505-531). New York, NY: John Wiley \& Sons. 